Research article

\title{
Reverse transcriptase-PCR differential display analysis of meningococcal transcripts during infection of human cells: Up-regulation of priA and its role in intracellular replication Adelfia Talà ${ }^{1}$, Mario De Stefano ${ }^{2}$, Cecilia Bucci ${ }^{1}$ and Pietro Alifano*1
}

Address: ${ }^{1}$ Dipartimento di Scienze e Tecnologie Biologiche ed Ambientali, Università degli Studi del Salento, Via Monteroni, 73100 Lecce, Italy and ${ }^{2}$ Dipartimento di Scienze Ambientali, Seconda Università degli Studi di Napoli, Via A. Vivaldi 43, 81100, Caserta, Italy

Email: Adelfia Talà - adelfia.tala@unile.it; Mario De Stefano - mario.destefano@unina2.it; Cecilia Bucci - cecilia.bucci@unile.it; Pietro Alifano* - alifano@ilenic.unile.it

* Corresponding author

Published: 29 July 2008

BMC Microbiology 2008, 8:131 doi:|0.1|86/|47|-2|80-8-|3|
Received: 16 February 2008

Accepted: 29 July 2008

This article is available from: http://www.biomedcentral.com/l47|-2180/8//31

(c) 2008 Talà et al; licensee BioMed Central Ltd.

This is an Open Access article distributed under the terms of the Creative Commons Attribution License (http://creativecommons.org/licenses/by/2.0), which permits unrestricted use, distribution, and reproduction in any medium, provided the original work is properly cited.

\begin{abstract}
Background: In vitro studies with cell line infection models are beginning to disclose the strategies that Neisseria meningitidis uses to survive and multiply inside the environment of the infected host cell. The goal of this study was to identify novel virulence determinants that are involved in this process using an in vitro infection system.
\end{abstract}

Results: By using reverse transcriptase-PCR differential display we have identified a set of meningococcal genes significantly up-regulated during residence of the bacteria in infected HeLa cells including genes involved in L-glutamate transport (gltT operon), citrate metabolism ( $g / t A)$, disulfide bond formation ( $d s b C)$, two-partner secretion (hrpA-hrpB), capsulation (lipA), and DNA replication/repair (priA). The role of PriA, a protein that in Escherichia coli plays a central role in replication restart of collapsed or arrested DNA replication forks, has been investigated. priA inactivation resulted in a number of growth phenotypes that were fully complemented by supplying a functional copy of priA. The priA-defective mutant exhibited reduced viability during late logarithmic growth phase. This defect was more severe when it was incubated under oxygenlimiting conditions using nitrite as terminal electron acceptors in anaerobic respiration. When compared to wild type it was more sensitive to hydrogen peroxide and the nitric oxide generator sodium nitroprusside. The priA-defective strain was not affected in its ability to invade HeLa cells, but, noticeably, exhibited severely impaired intracellular replication and, at variance with wild type and complemented strains, it co-localized with lysosomal associated membrane protein I.

Conclusion: In conclusion, our study i.) demonstrates the efficacy of the experimental strategy that we describe for discovering novel virulence determinants of $N$. meningitidis and ii.) provides evidence for a role of priA in preventing both oxidative and nitrosative injury, and in intracellular meningococcal replication.

\section{Background}

Neisseria meningitidis (meningococcus) is a transitory colonizer of the human nasopharynx that sporadically pro- vokes life-threatening disease. This microorganism has to interact with cellular barriers for its life cycle [1]. After crossing the nasopharyngeal mucosa, meningococci occa- 
sionally spread into the blood stream before moving across the blood-brain barrier causing fatal sepsis and meningitis in otherwise healthy individuals [2-5].

The early stages of an infection with $N$. meningitidis are governed by specific interactions between the pathogen and the epithelial tissues and are quite well known. Indeed, this microorganism has evolved a diverse array of surface structures subjected to phase- and antigenic-variation, which promote adherence and entry into human cells, although it is still unclear whether cell invasion is important in human infections. Initial adherence of encapsulated bacteria requires type IV pili, fine hair-like structures protruding from the bacteria surface [3]. Then, interaction with host cells is achieved by several meningococcal surface adhesins (Opa and Opc) that have been extensively studied $[1,6]$. In contrast, later stages of infection, including the intracellular location of the meningococci and their strategies for intracellular survival, are only poorly understood [1].

In vitro studies with cell line infection models are beginning to disclose the essential role of the metabolic adaptation of meningococci to the intracellular environment of the infected cell. The adaptive response includes the stimulation of the capsular biosynthetic genes leading to increased resistance to cationic antimicrobial peptides (CAMPs), important components of the host innate defense system against microbial infections [7], and the activation of the GdhR regulon whose members are involved in metabolism of the available host carbon sources $[8,9]$.

In this work by using reverse transcriptase-PCR differential display (RT-PCR-DD) we have identified a set of meningococcal genes up-regulated during residence of the bacteria in the intracellular host environment including genes involved in L-glutamate transport (glt T operon), citrate metabolism $(g l t A)$, disulfide bond formation $(d s b C)$, two-partner secretion (hrpA-hrpB), capsulation (lipA), and DNA replication/repair (priA). PriA is a single-stranded DNA-dependent ATPase, and a 3' to 5' DNA translocase/ helicase that was discovered originally because of its requirement in vitro for the conversion of bacteriophage phiX174 viral DNA to the duplex replicative form $[10,11]$. In Escherichia coli this protein, at the crossroads of DNA replication and recombination, plays a central role in origin-independent, replication restart of collapsed or arrested DNA replication forks and is also involved in DNA recombination [12-14]. These activities rely on the ability of PriA to load replication forks at a D loop, an intermediate that forms during homologous recombination, double-strand break-repair, and stable DNA replication. We investigated the role of priA in the meningococcal infectious cycle using a human cell line infection model.

\section{Results \\ RNA differential display analysis of meningococcal gene expression in the intracellular host environment}

In an attempt to identify meningococcal genes selectively up- or down-regulated in the intracellular environment of infected host cells we used a previously published RTPCR-DD strategy that relies on the presence of highly and moderately repetitive transcribed DNA sequences in the meningococcal genome [8]. Oligonucleotides designed on the basis of the DUS (DUS-IN and DUS-OUT) or the 26L, 27L nemis sequences (26L-IN, 26L-OUT, 27L-IN, 27L-OUT) were used as primers in reverse-transcriptase (RT) assays to prepare cDNAs from intracellular meningococci (strain B1940) recovered from saponin-lysed HeLa cells after $7 \mathrm{~h}$ of infection or control bacteria grown in DMEM without HeLa cells as previously described [7]. After $7 \mathrm{~h}$ of infection bacterial recovery from infected cells reached the highest values [7]. We decided to use HeLa cells because studies with these cells have contributed to our understanding of the molecular mechanisms underlying the infectious cycle of $N$. meningitidis [15-20]. The analysis of the meningococcal transcriptome during the early stages of an infection has been previously performed using HeLa cells [21].

The cDNAs from intracellular meningococci were then amplified by PCR using the corresponding oligonucleotides and a mixture of random hexamers as primers, and the PCRs were analyzed by polyacrylamide gel electrophoresis. By this approach, several bands corresponding to either up-regulated ( $a, c, d, e, f, g, l, m, n, o)$ or downregulated genes $(\mathbf{b}, \mathbf{h}, \mathbf{i})$ were detected in the intracellular bacteria (Fig. 1A). The bands $\mathbf{a}, \mathbf{c}, \mathbf{f}, \mathbf{g}, \mathbf{l}$ and $\mathbf{n}$ were then excised from the gels, the corresponding cDNAs were cloned and subjected to nucleotide sequences analysis. Three clones were sequenced form each band. The bands $\mathbf{d}_{-}, \mathbf{e}-, \mathbf{m}-$, and o-associated cDNAs, when subjected to cloning, each gave rise to more than one clone, and therefore they were not further analyzed in this study. Bands corresponding to down-regulated genes were not examined.

The nucleotide sequence analysis demonstrated that the band $\mathbf{a}$ - and $\mathbf{f}$-associated cDNA corresponded to genes that have been shown to be induced in the intracellular environment and have been also implicated in meningococcal pathogenesis (Fig. 1C). The band a-associated cDNA corresponded to NMB1964, a gene of the GdhRregulated glt $T$ operon coding for the L-glutamate $\mathrm{ABC}$ transporter that is critical for meningococcal adaptation in the low-sodium intracellular environment [8]. The band $\mathbf{f}$ corresponded to NMB0082 coding for LipA, a protein required for proper translocation and surface expression of the lipidated $(\alpha 2 \rightarrow 8)$-linked polysialic acid capsule polymer $[7,22]$. The band g-associated cDNA sequence fell within NMB1780-NMB1779 (hrpB-hrpA) operon cod- 
A

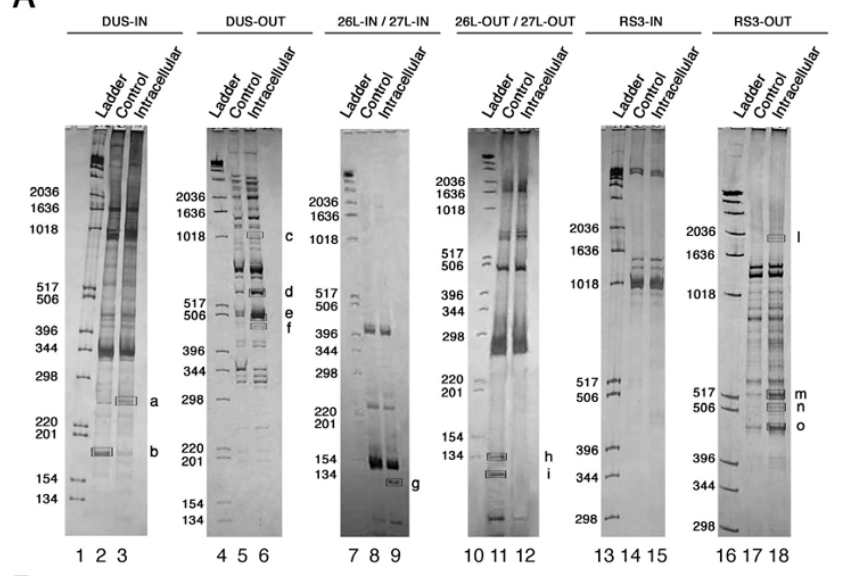

B

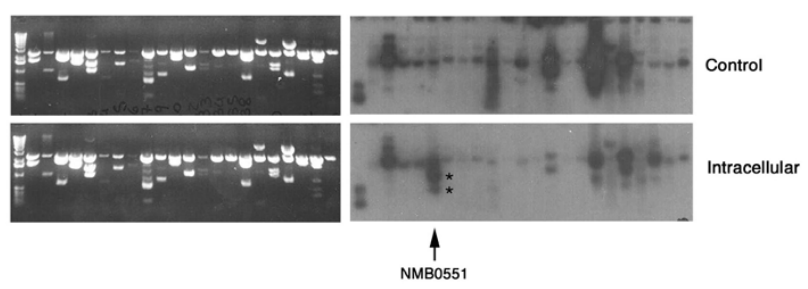

C

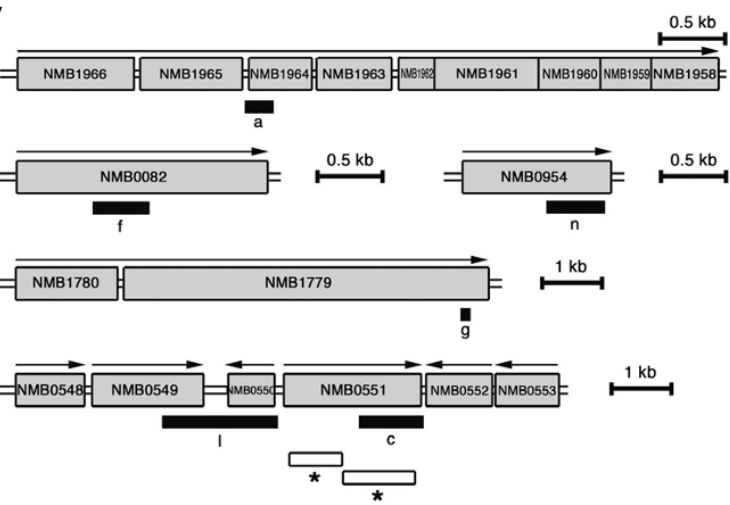

Figure I

RT-PCR-DD and limited transcriptional analysis of meningococcal transcripts up- and down-regulated during the intracellular phase. (A) RT-PCR-DD analysis. Oligonucleotides DUS-IN, DUS-OUT, RS3-IN, RS3-OUT or oligonucleotide mixtures 26L-IN/27L-IN, 26L-OUT/27L-OUT were used as primers in first-strand cDNA synthesis using total RNAs from intracellular meningococci (strain B 1940) recovered from saponin-lysed HeLa cells after $7 \mathrm{~h}$ of infection (intracellular) or control bacteria grown for $7 \mathrm{~h}$ in cell culture medium without HeLa cells (control) as templates. Then second-strand cDNAs synthesis was carried out using the corresponding oligonucleotides and a mixture of random hexamers as primers, and the PCR products were analyzed by polyacrylamide gel electrophoresis. In lanes I and 6 molecular weight ladders, whose sizes are indicated on the left of each panel, were run in parallel. The arrows indicate bands corresponding to either up-regulated (a, c, $\mathbf{d}, \mathbf{e}, \mathbf{f}, \mathbf{g}, \mathbf{I}, \mathbf{m}, \mathbf{n}, \mathbf{o})$ or down-regulated genes $(\mathbf{b}, \mathbf{h}, \mathbf{i})$ in the intracellular environment. Molecular weight DNA ladders were run in parallel. (B) Limited transcriptional analysis. A partial Sau3Al-restricted genomic library from the strain BI940 was constructed. Individual plasmid clones were digested with Sau3AI and a Southern blot analysis was performed using $32 \mathrm{P}$-labeled cDNA probes derived from intracellular bacteria after $8 \mathrm{~h}$ of infection of HeLa cells or control bacteria grown for $8 \mathrm{~h}$ in cell culture medium. In the figure only a limited number of clones (22 clones out of 3000) on duplicate filters are shown. The arrow indicates the cloned NMB055 I ORF corresponding to priA, up-regulated by intracellular meningococci. Asterisks mark the 983 and I I 23 bp-long Sau3AI fragments contained in the plasmid clone. (C) Genetic map of meningococcal genes up-regulated in the intracellular environment. The positions of the cDNAs (closed rectangles) corresponding to up-regulated genes that were identified by RT-PCR-DD (a, $\mathbf{c}, \mathbf{g}, \mathbf{f}, \mathbf{I}, \mathbf{n})$ are indicated with respect to the available genetic map of MC58. Open rectangles with asterisks locate the 983 and I I 23 bp-long Sau3Al fragments contained in the priA plasmid clone shown in panel B. 
ing for a two-partner secretion (TPS) system that has been recently shown to contribute to adhesion of un-encapsulated bacteria to epithelial cells [23]. The bands c-, l- and $\mathbf{n}$-associated cDNAs corresponded to genes whose role in meningococcal pathogenesis has never been reported so far, including NMB0551 (band c sequence) encoding PriA, the linked NMB0549 and NMB0550 (band 1 sequence) coding, respectively, for a thiol-disulfide oxidoreductase (DsbC) and the ATP-binding protein of an unknown ABC-type transporter (YbjZ), and NMB0954 (band $\mathbf{n}$ sequence) encoding GltA, the putative meningococcal citrate synthase (Fig. 1C). Fig. 1C also shows the genes surrounding priA (NMB0551). Upstream from NMB0549 $(\gamma b j Z)$ a gene coding for an AcrA/AcrE family protein (NMB0548) is located; downstream to priA and in the opposite direction a gene coding for a protein of unknown function (NMB0552) and that for a putative transposase (NMB0553) map.

\section{The role of priA in meningococcal pathogenesis}

The role of PriA in meningococcal pathogenesis was explored in more detail using the HeLa infection model. It is noteworthy that over-expression of priA was also observed in an independent screening by limited transcriptional analysis (Fig. 1B) that was useful to demonstrate up-regulation of lipA in a previous work [7]. This screening was performed using a partial Sau3AI-restricted genomic library from B1940. The library was screened by Southern blot using cDNA probes derived from intracellular bacteria after $8 \mathrm{~h}$ of infection of HeLa cells or control bacteria grown for $8 \mathrm{~h}$ in cell culture medium. The screening led to isolation of a plasmid harboring two Sau3AI fragments, 983 and 1123 bp-long (marked by asterisks in Fig. $1 \mathrm{~B}$ and $1 \mathrm{C}$ ), spanning almost the entire priA gene.

Nevertheless, in order to confirm the results of the RTPCR-DD analysis, slot blot and RT real-time PCR experiments were performed (Fig. 2). Semi-quantitative analysis by slot blot experiments demonstrated that the priA-specific RNA was about three-fold more abundant in meningococci recovered from saponin-lysed HeLa cells than in control bacteria grown in DMEM without HeLa cells (Fig. 2A-B). This result was confirmed by RT real-time PCR demonstrating an about four-fold increase in the amount of priA transcripts in intracellular meningococci (Fig. 2C). It should be noted that RT-PCR-DD, limited transcriptional analysis and RT real-time PCR were performed on RNAs from different sets of infection experiments thus enhancing the argument for a role of this gene in the intracellular environment.

To gain functional information about the role of priA in $N$. meningitidis, we decided to inactivate it insertionally by transformation with pDEXpriA (Fig. 3A and Materials and Methods). Southern blot analysis confirmed the insertion of this suicide plasmid into the priA coding region by a single cross-over event (Fig. 3B). As a result of the recombination event, two HinfI DNA fragments of the expected sizes ( 4019 bp and 852 bp) were detected by priA-specific

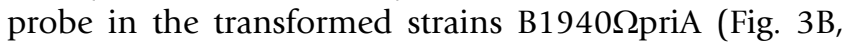
lanes 1-3) in place of the $1568 \mathrm{bp}$ Hinfl fragment of the parental strain B1940 (Fig. 3B, lane 4). In order to be sure that priA inactivation was causal to all of the phenotypes observed below, a functional copy of priA was introduced

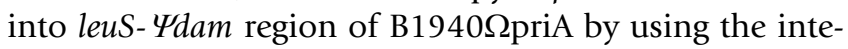
grative plasmid pACpriA. Successful gene delivery was demonstrated by Southern blot analysis (Fig. 3C). In two

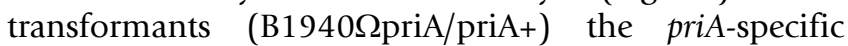
probe detected the presence of both the $1568 \mathrm{bp} \mathrm{HinfI}$ fragment (typical of the wild type priA) and the $4019 \mathrm{bp}$ and $852 \mathrm{bp} \mathrm{Hinfl}$ fragments (typical of the inactivated priA) (Fig. 3C, lanes 3 and 4).

Phenotypic analysis demonstrated that priA inactivation resulted in a growth defect. Indeed, under aerobic condi-

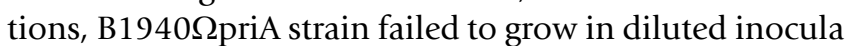
$\left(=\right.$ or $\left.<10^{6} \mathrm{CFU} \mathrm{ml}{ }^{-1}\right)$, but when it was inoculated at higher densities $\left(=\right.$ or $>10^{7} \mathrm{CFU} \mathrm{ml}{ }^{-1}$ ) it grew at rates similar to those of the parental strain (Fig. 4A). However, in high-

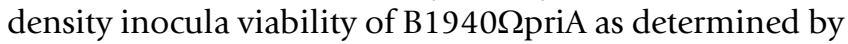
CFU was apparently reduced when compared to that of B1940. In the experiment shown in Fig. 4C, left panel,

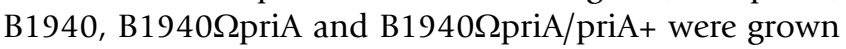
aerobically in liquid GC medium to late logarithmic phase $\left(1.0 \mathrm{OD}_{600 \mathrm{~nm}}\right)$. Then, serial dilutions of the cultures were plated on GC agar, incubated aerobically in the presence of $5 \% \mathrm{CO}_{2}$, and the number of CFU determined after $24 \mathrm{~h}$. Results demonstrated small colony size (Fig. 4C) and reduced colony number (to about $34 \%$ ) of the priAdefective strain compared to the parental one (Fig. 4B). This phenotype was much more severe when GC agar plates containing nitrite were incubated under either aerobic (not shown) or oxygen-limiting conditions (Fig. 4C, right panel). Under both these conditions the colony

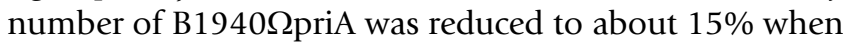
compared to that of B1940 under the same conditions (Fig. 4B). Statistical analysis with the Student's T-test confirmed that the growth defects in the presence of nitrite or in oxygen limited conditions in the presence of nitrite were more severe than under aerobic conditions without

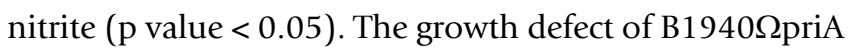
was not observed during middle logarithmic phase (data not shown), and could be completely restored by comple-

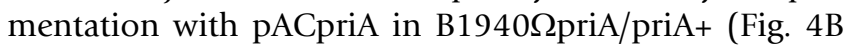
and $4 \mathrm{C}$ ).

We next investigated the mechanism underlying the

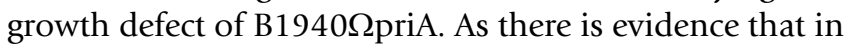
E. coli priA inactivation results in defective cell division that generates long filaments [24], we used scanning elec- 
tron microscopy (SEM) to analyze morphology

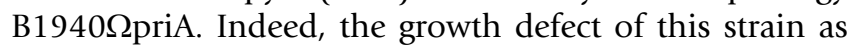
determined by CFU method might have been caused by a cell division defect that in meningococci, which divide in alternating planes generates clumps. However, SEM analysis did not reveal any difference between the wild type and the priA-defective strain grown to late logarithmic phase $\left(1.0 \mathrm{OD}_{600 \mathrm{~nm}}\right)$ (Fig. 5).

To confirm the hypothesis that the growth impairment of

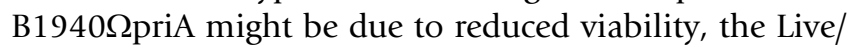
Dead staining assay was carried out. This assay employs two fluorescent nucleic acid stains, SYTO9 and propidium iodide, which differ in their ability to penetrate healthy bacterial cells. When used alone, the green-fluorescent SYTO 9 stain labels both live and dead bacteria. In contrast, the red-fluorescent propidium iodide stain penetrates only bacteria with damaged membranes, reducing SYTO 9 fluorescence when both dyes are present. Thus, live bacteria fluoresce green, while dead bacteria fluoresce red (Fig. 6A). Using this system we did not observe any significant changes in viability between B1940 and

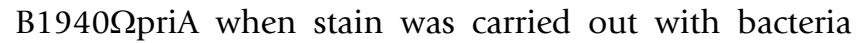
grown in GC medium to middle logarithmic phase $(0.5$ $\left.\mathrm{OD}_{600 \mathrm{~nm}}\right)$. Indeed, the percentage of nonviable cells was approximately $10 \%$ for both strains. In contrast,

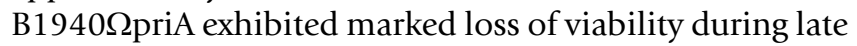
logarithmic phase $\left(1.0 \mathrm{OD}_{600 \mathrm{~nm}}\right)$ when the percentage of nonviable cells approximated 35\% (Fig. 6B). The defect in viability was completely restored by complementation (Fig. 6A and 6B). The Live/Dead staining assay also confirmed the absence of any cell division defect in

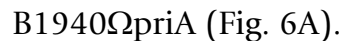

Assessment of viability after exposure to hydrogen peroxide (Fig. 7A) or the nitric oxide generator sodium nitro-

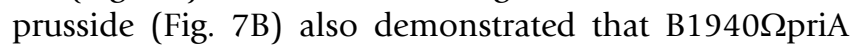
was much more sensitive to oxidative and nitrosative injuries when compared to the parental strain. The phenotype could be complemented back to wild type levels in

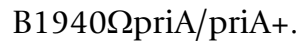

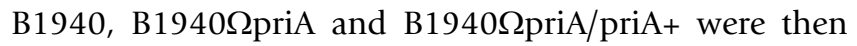
used in cell invasion and intracellular persistence assays. In these experiments, high density-inocula of meningococci were used and infections were initiated by using comparable numbers of viable bacteria for both strains as determined by both CFU method and Live/Dead staining. After allowing meningococci to invade HeLa cells for $1 \mathrm{~h}$, intracellular viability was assessed immediately after gentamicin (time $0 \mathrm{~h}$ ) treatment and 3, 5 and $7 \mathrm{~h}$ post-gentamicin treatment (Fig . 8). Results demonstrated the absence of statistically relevant differences in the ability to invade the HeLa cells by the three strains (Fig. 8, time $0 \mathrm{~h}$ ). At $3 \mathrm{~h}$ post-gentamicin treatment the number of recovera- ble wild type, mutant and complemented bacteria dropped about ten-fold. Normally, at this time, a decrease occurs in intracellular viable bacteria, which is also characteristic of gonococcal invasion $[7,8,25,26]$. Between 3

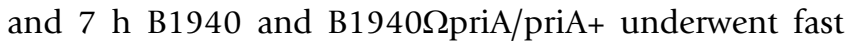
duplication and the number of viable bacteria increased more than 50-fold. In particular, intracellular duplication was extremely fast during the first $2 \mathrm{~h}$ after gentamicin treatment (time 3-5 h) with an apparent generation time of about $24 \mathrm{~min}$ and slower during the last $2 \mathrm{~h}$ (time 5-7) consistent with previous findings $[7,8]$. In contrast,

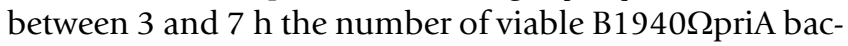
teria increased less than 10-fold with an apparent generation time of 96 min during the first $2 \mathrm{~h}$ after gentamicin treatment (time 3-5 h). It should be noted that intracellular generation times are only apparent, as they reflect the sum of intracellular growth, intracellular death and, eventually, bacterial egression from HeLa cells and re-invasion. Therefore different processes may be affected in this mutant.

To further investigate the origin of the growth/survival

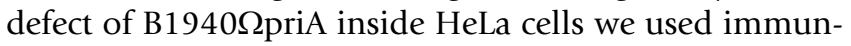
ofluorescence microscopy. Intriguingly, we noted that number of intracellular priA-defective bacteria $7 \mathrm{~h}$ after infection was about the same as those of wild type and complemented bacteria (Fig. 9 and data not shown). This seemed to be in contrast with the data obtained with the CFU method showing a marked decrease in the number of intracellular priA-defective bacteria $7 \mathrm{~h}$ after infection (Fig. $8)$. However, in contrast to CFU method, immunofluorescence analysis detects even dead bacteria, and this means that most priA-defective meningococci inside HeLa cells were actually not viable. The evidence that, at variance with wild type and complemented bacteria, most priA mutant bacteria co-localized with the lysosomal associated membrane protein 1 (LAMP1) strongly supported this hypothesis. This finding is noteworthy because live meningococci have been shown to use IgA protease to cleave LAMP1 protein [27], accounting for the lack of colocalization of wild type and complemented bacteria with this marker. On the basis of this evidence we concluded that the growth phenotype of the priA-defective mutant inside HeLa cells was mostly due to reduced viability than to reduced growth rate.

\section{Discussion}

The goal of our study was to assess the reliability of RTPCR-DD as a tool to identify genes with increased or decreased expression during meningococcal growth in infected cells. Although this analysis was clearly not exhaustive as the repeat sequences that we used to prime the RT-PCR-DD reactions were not randomly distributed in the chromosome, and not found in every gene [28], nevertheless it enabled us to identify three up-regulated 
A
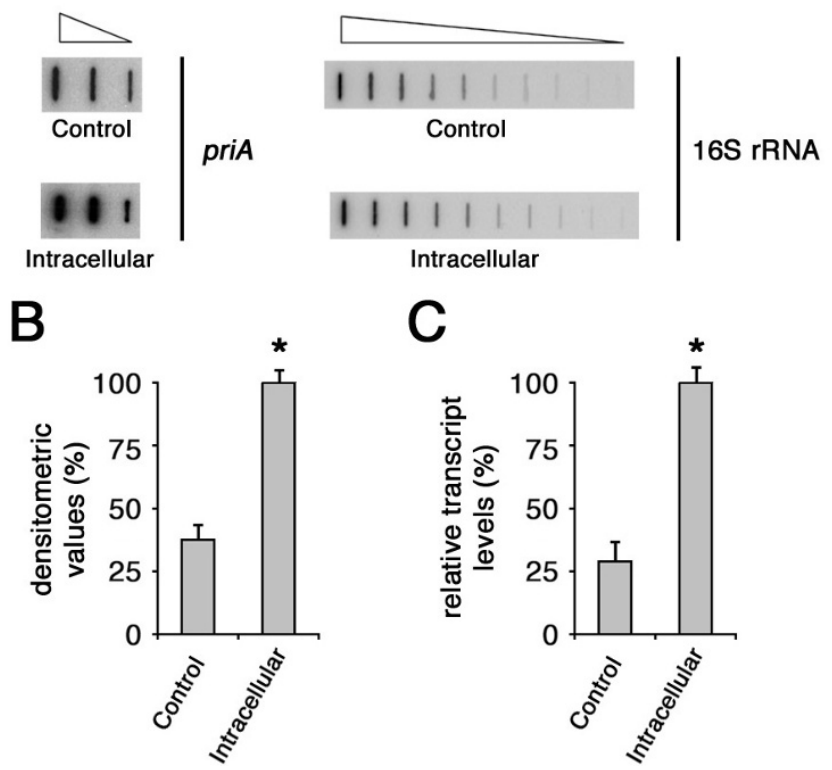

Figure 2

Semi-quantitative analysis of priA-specific transcripts in intracellular meningococci. (A) RT-PCR slot blot anal$y$ sis of the priA-specific transcripts. Total RNAs were extracted from meningococci (strain B 1940) after $7 \mathrm{~h}$-infection of HeLa cells (intracellular), or control bacteria grown for $7 \mathrm{~h}$ in culture medium (control) and were used to generate gene-specific ${ }^{32} \mathrm{P}$-labeled CDNA probes as detailed in the Methods section. The ${ }^{32 P}$-labeled cDNA probes were hybridized to different amounts $(4,20$ and $100 \mathrm{ng})$ of denatured NMB055 I (priA)-specific DNA fragments. For the 16S rRNA gene-specific fragment, two-fold serial dilutions (from 0.05 to $50 \mathrm{ng}$ ) were used. (B) Densitometry analysis of the RT-PCR slot blot with $20 \mathrm{ng}$ of priA-specific DNA fragments. The relative transcript levels of priA in intracellular meningococci are arbitrarily assumed equal to $100 \%$. Values represent means from five independent experiments, each with triplicate samples, using RNA preparations from distinct infection assays. Bars indicate standard deviations. (C) Semiquantitative analysis of the priA-specific transcripts by RT real-time PCR experiment. The RNAs were extracted from intracellular or control meningococci as described above. Results were normalized to $16 \mathrm{~S}$ rRNA levels. Transcript levels of priA in intracellular meningococci were arbitrarily given a value of $100 \%$. Data are shown as mean \pm standard deviation from five independent experiments, each with triplicate samples, using RNA preparations from distinct infection assays. The Student's T-test was used for statistical analysis. Statistically significant differences between values from intracellular and control bacteria (asterisks) are declared at a $\mathrm{P}$ value $<0.05$.

genes/operons ( $g l t T$, lipA, hrpA-hrpB) with known roles in virulence (thus validating this approach) and three novel potential meningococcal virulence factors (Fig. 1). One of

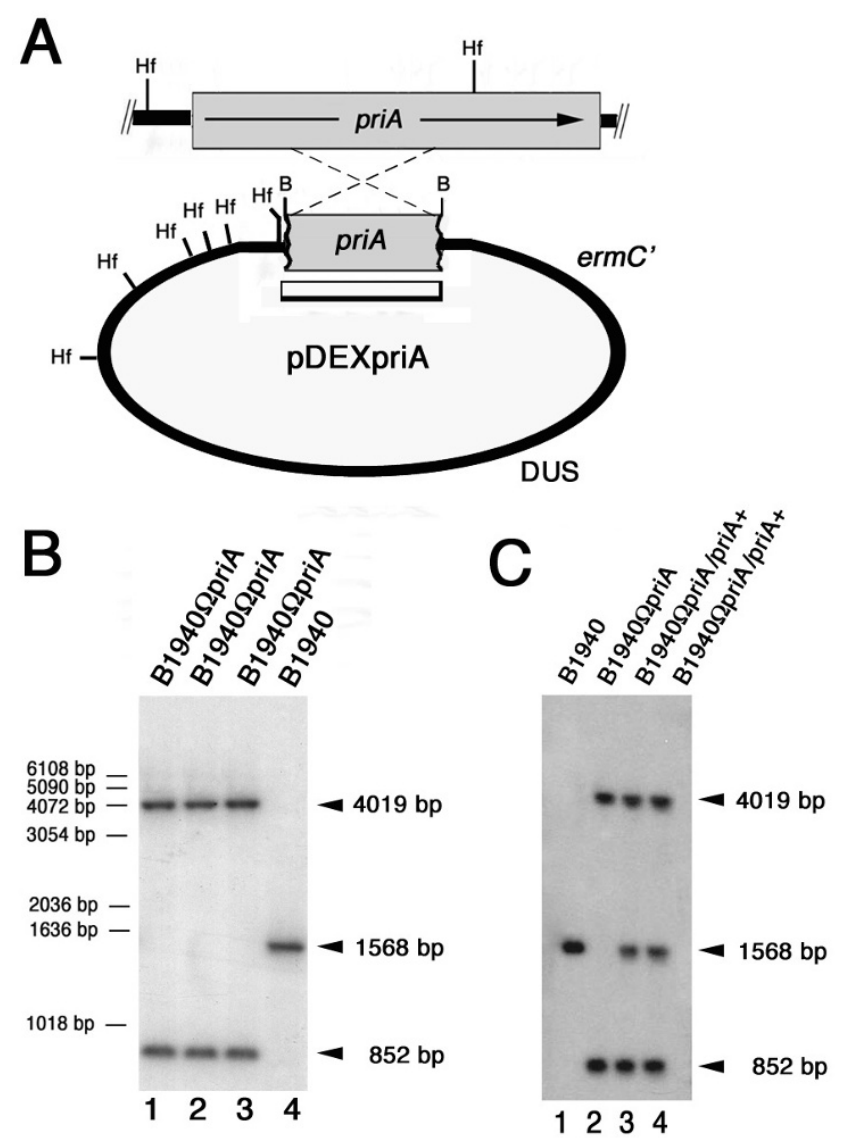

Figure 3

Knockout of NMB055 I (priA) and complementation. (A) Experimental design for priA disruption by single cross over. The genetic and physical map of the priA gene is depicted above the map of the PDEXpriA region involved in single cross-over and the probe (open rectangle) used in the Southern blot experiments shown in panels B and C. ermC', erythromycin-resistance gene; DUS, DNA uptake sequence; B, BamHI restriction sites; $\mathrm{Hf}$, Hinfl restriction sites. (B) Southern blot analysis demonstrating the inactivation of priA. Chromosomal DNAs were extracted from the parental strain B 1940 (lane 4) and from three recombinant strains

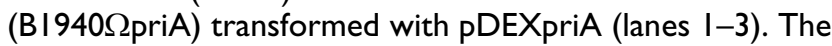
Hinfl-restricted chromosomal DNAs were analyzed by Southern blot using the ${ }^{32} \mathrm{P}$ labeled priA-specific DNA fragments cloned in PDEXpriA as probes. The arrows on the right indicate priA-specific fragments whose sizes were deduced on the basis of the relative migration of DNA ladders (bars on the left). (C) Southern blot experiment demon-

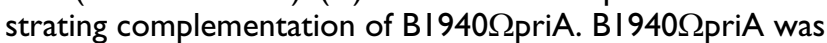
transformed with $\mathrm{pAC}$ priA harboring a functional copy of priA, and chromosomal DNAs were extracted from two

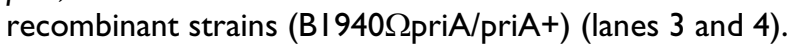
The DNAs from these two strains, from B 940 (lane I) and

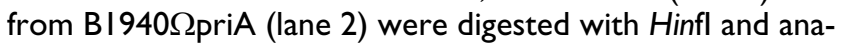
lyzed as in panel $B$. 
these, priA, was selected for extensive further validation (Fig. 2) and characterization.

In infected cells meningococci have to adapt their metabolism to the available host carbon and nitrogen sources and circumvent or subvert a number of host defense mechanisms including lysosomal killing, antimicrobial peptides and oxidative injury. Up-regulation of the gltT operon, coding for an L-glutamate $\mathrm{ABC}$ type transporter that is critical for meningococcal adaptation in the lowsodium intracellular environment [8], and of gltA, coding for the citrate synthase, catalyzing the first committed step of the citric acid cycle is part of a metabolic strategy to survive and grow in the intracellular environment. Indeed, in the intracellular milieu there is little available glucose, as glucose entering cells is rapidly phosphorylated to glucose-6-phosphate [29], a substrate that, as well as the other glycolytic intermediates, cannot be assimilated by meningococci. The best intracellular carbon sources are pyruvate and lactate or/and several amino acids such as Lglutamate that stimulate the citric acid cycle $[26,30]$.

Stimulation of L-glutamate uptake and respiratory metabolism is also useful to prevent oxidative injury, a major source of DNA damage, as this amino acid is the precursor of glutathione [29]. In this context the up-regulation of thiol-disulfide oxidoreductase (DsbC)- and PriA-encoding genes (Figs. 1 and 2), and the impaired ability of the priA-defective mutant to replicate in infected HeLa cells (Figs. 8 and 9) may be relevant. PriA plays a central role in origin-independent replication restart of collapsed or arrested DNA replication forks [12-14]. There is evidence that, even under normal aerobic conditions, most, if not all, replication forks do not proceed from the origin of replication to the terminus without hitting a roadblock, in the form of a damaged DNA template, a nick in the template, a "frozen" protein-DNA complex, or local positive superhelicity, which have the potential to arrest or collapse the fork. Inability to reassemble the replisome and resume replication in a timely manner after repair of DNA damage can lead to chromosomal rearrangements and consequently, a loss in viability [31].

Oxidative injury is a major cause of DNA replication fork arrest [32]. This accounts for the growth defect mostly due to reduced viability of the priA-defective meningococcal strain (Figs. 4 and 6), which was much more sensitive to oxidative and nitrosative injuries when compared to the parental strain (Fig. 7). Reduced viability was also observed in E. coli priA-defective mutants [24,33]. A growth defect was also shown in the Neisseria gonorrhoeae priA-defective mutant [34]. This strain was also defective in DNA repair and DNA transformation compared to the isogenic parental strain. However, based on staining with Live/Dead BacLight kit the authors concluded that the
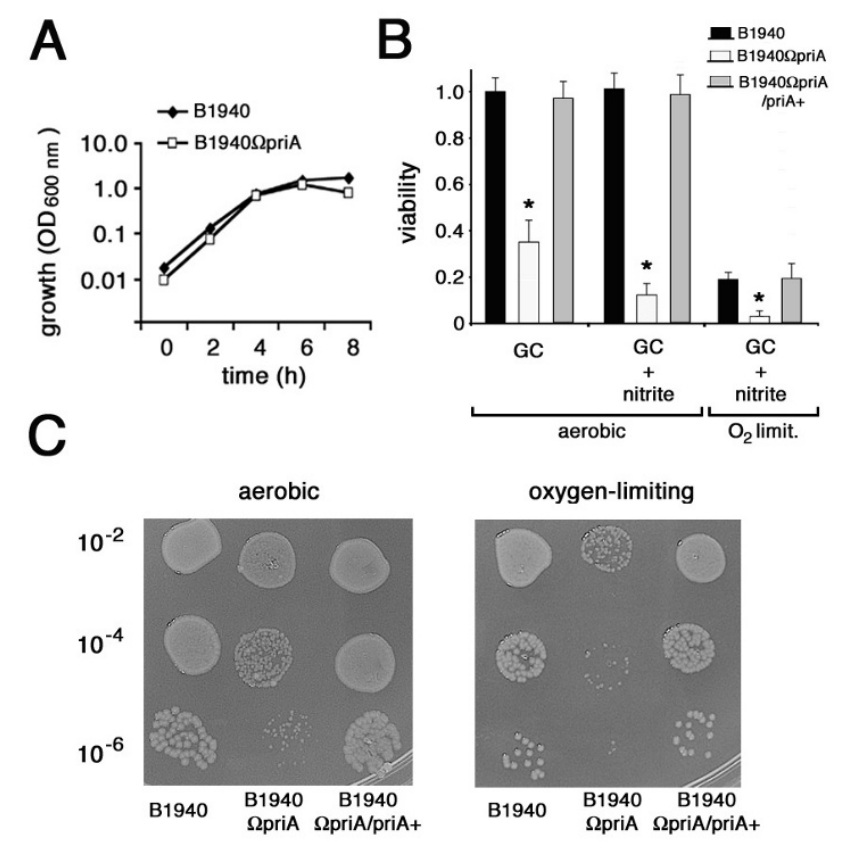

\section{Figure 4}

Effects of priA inactivation on meningococcal growth.

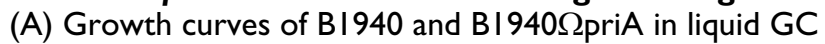
medium. (B and $C$ ) Viability of meningococcal cells as determined by CFU method. Serial dilutions $\left(10^{-2}\right.$ to $\left.10^{-6}\right)$ of

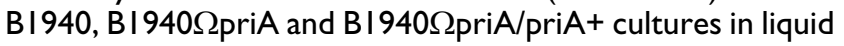
GC medium were plated on either GC agar or GC agar containing $5 \mathrm{mM}$ sodium nitrite and incubated aerobically in the presence of $5 \% \mathrm{CO}_{2}$; parallel dilutions were plated on $\mathrm{GC}$ agar containing $5 \mathrm{mM}$ sodium nitrite and incubated under oxygen-limiting conditions. CFU were determined after $24 \mathrm{~h}$. Viability of B 1940 grown aerobically is arbitrarily assumed equal to I.0. Data are shown as mean \pm standard deviation from five independent experiments, each with triplicate samples. The Student's T-test was used for statistical analysis. Statistically significant differences between values from BI 940

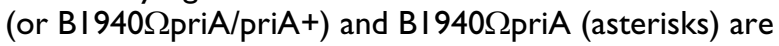
declared at a $p$ value $<0.05$. Note in $C$ the small colony size and the reduced colony number of the priA-defective mutant compared to the wild type and complemented strains.

growth defect could not be attributable to reduced viability. The different biology of the meningococcal and gonococcal infection may account for the different phenotype of the meningococcal and gonococcal priA-defective mutants. Indeed, substantial differences in oxidative defenses between meningococci and gonococci have been reported. When compared to meningococci, gonococci that are usually associated with inflamed urogenital tissues and activated polymorphonuclear leukocytes, have much higher catalase and cytochrome c peroxidase activities in addition to a specific manganese (II) uptake system involved in resistance to superoxide radicals [35]. 
The growth defect of the priA-defective meningococcal strain was more severe in the presence of nitrite under either aerobic or oxygen-limiting growth conditions (Fig. 4). Under these conditions meningococci use nitrite as a terminal electron acceptor in anaerobic respiration. Nitrite reduction via nitric oxide to nitrous oxide is the partial denitrification pathway for this mode of growth. In pathogenic Neisseriae the pathway involves both a coppercontaining nitrite reductase (AniA) and a single subunit nitric oxide reductase (NorB) [36,37]. Nitrite reduction leads to the production of nitric oxide, a toxic molecule that exhibits synergistic activity in combination with reactive oxygen species [38] and that in Salmonella induces DNA replication arrest [39]. The inability to restart nitric oxide-promoted arrested replication forks may account for reduced viability of the priA-defective mutant under oxygen-limiting conditions.

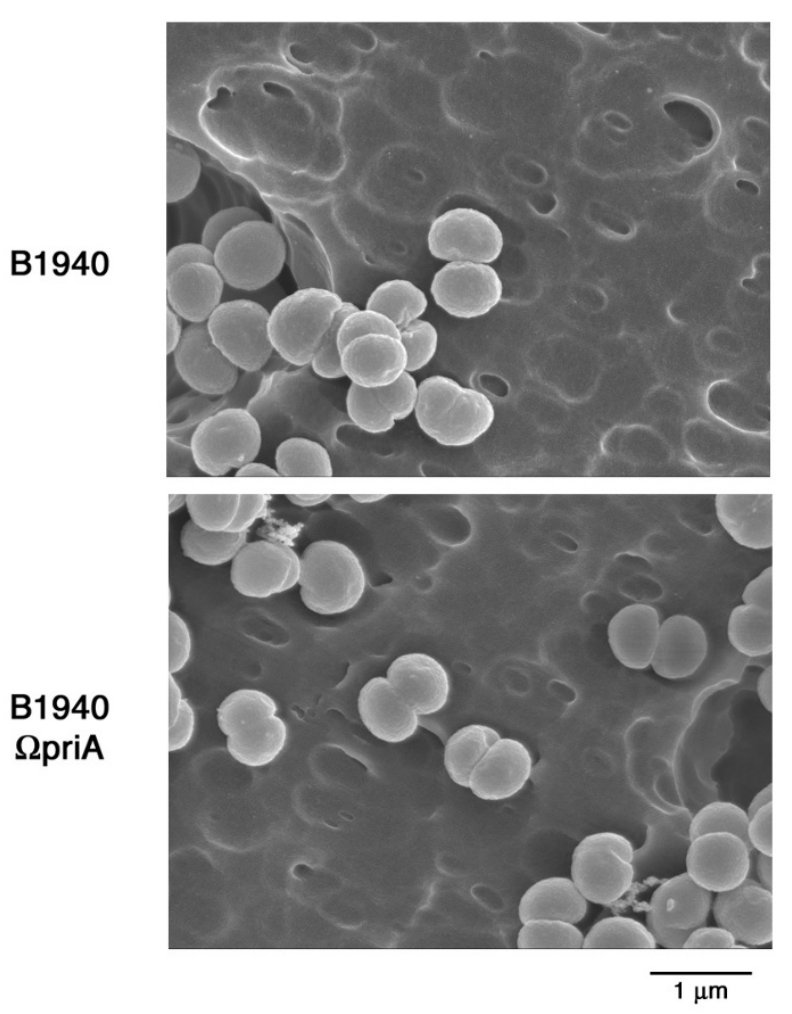

\section{Figure 5}

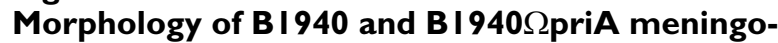
cocci. Meningococcal strains BI940 and B $940 \Omega$ priA were grown to late $\left(1.0 \mathrm{OD}_{600 \mathrm{~nm}}\right)$ logarithmic phase and observed by scanning electron microscopy. Note that priA-inactivation does not affect the typical diplococcal, coffee bean-shaped morphology of meningococci.
The relevance of nitrite reduction and defence mechanisms against nitric oxide injury in neisserial pathogenesis is the subject of investigation. Nitrite is present in the diet and is naturally formed in human blood and tissues due to the oxygenation of nitric oxide that is produced by various cell types as a signaling molecule and as a weapon against pathogens and tumor cells. It has been proposed that in microaerobic environments including the human nasopharynx and in the nitric oxide-enriched intracellular environment, meningococcal partial denitrification contributes with oxygen respiration as a route for electron transfer in respiration $[37,40]$. Interestingly, inside HeLa cells at variance with wild type and complemented bacteria, priA-defective meningococci co-localized with LAMP1 (Fig. 9) that marks highly oxidative and nitrosative cell compartments [41]. Based on this evidence, it is reasonable to assume that failure of the priA-defective mutant to replicate efficiently in HeLa cells may reflect the reduced ability to restart arrested replication forks.

\section{Conclusion}

In conclusion, in this study we, on one hand, demonstrate the efficacy of the experimental strategy that we describe, i.e. the analysis of the meningococcal gene expression, for disclosing the mechanisms that $N$. meningitidis uses to survive and multiply inside the environment of the human cell. On the other hand, we provide evidence that priA, whose expression increases in the intracellular environment, plays a key role in preventing both oxidative and nitrosative injuries, and in intracellular meningococcal replication.

\section{Methods \\ Bacterial strains and growth conditions}

N. meningitidis serogroup B strain B1940 was used in this study. The origin and genotype of this strain have been previously reported [42]. Meningococci were cultured either aerobically in GC broth or agar with 1\% Polyvitox, at $37^{\circ} \mathrm{C}$ in a $5 \% \mathrm{CO}_{2}$ incubator or under oxygen-limiting conditions in GC agar containing $5 \mathrm{mM}$ sodium nitrite with $1 \%$ Polyvitox, at $37^{\circ} \mathrm{C}$ in an anaerobic jar with an anaerobic atmosphere generator (GENbox anaer, Biomerieux) and an indicator (Anaer indicator, Biomerieux).

E. coli strain DH5 $\alpha$ [F-Ф80d lacZAM15 endA1 recA1 hsdR17 supE44 thi-1 $\lambda$-gyrA96 $\triangle$ (lacZYA-argF) U169] was used in cloning procedures. This strain was grown in Luria Bertani (LB) medium. To allow plasmid selection, the LB medium was supplemented with ampicillin $\left(50 \mu \mathrm{g} \mathrm{ml}^{-1}\right)$.

\section{Cell culture and infection}

For standard invasion and intracellular viability assays, HeLa cells (ATCC Number CCL-2) were used. Several experiments were also repeated with HEp2 (ATCC Number CCL-23) and Chang conjunctiva cells (ATTC 


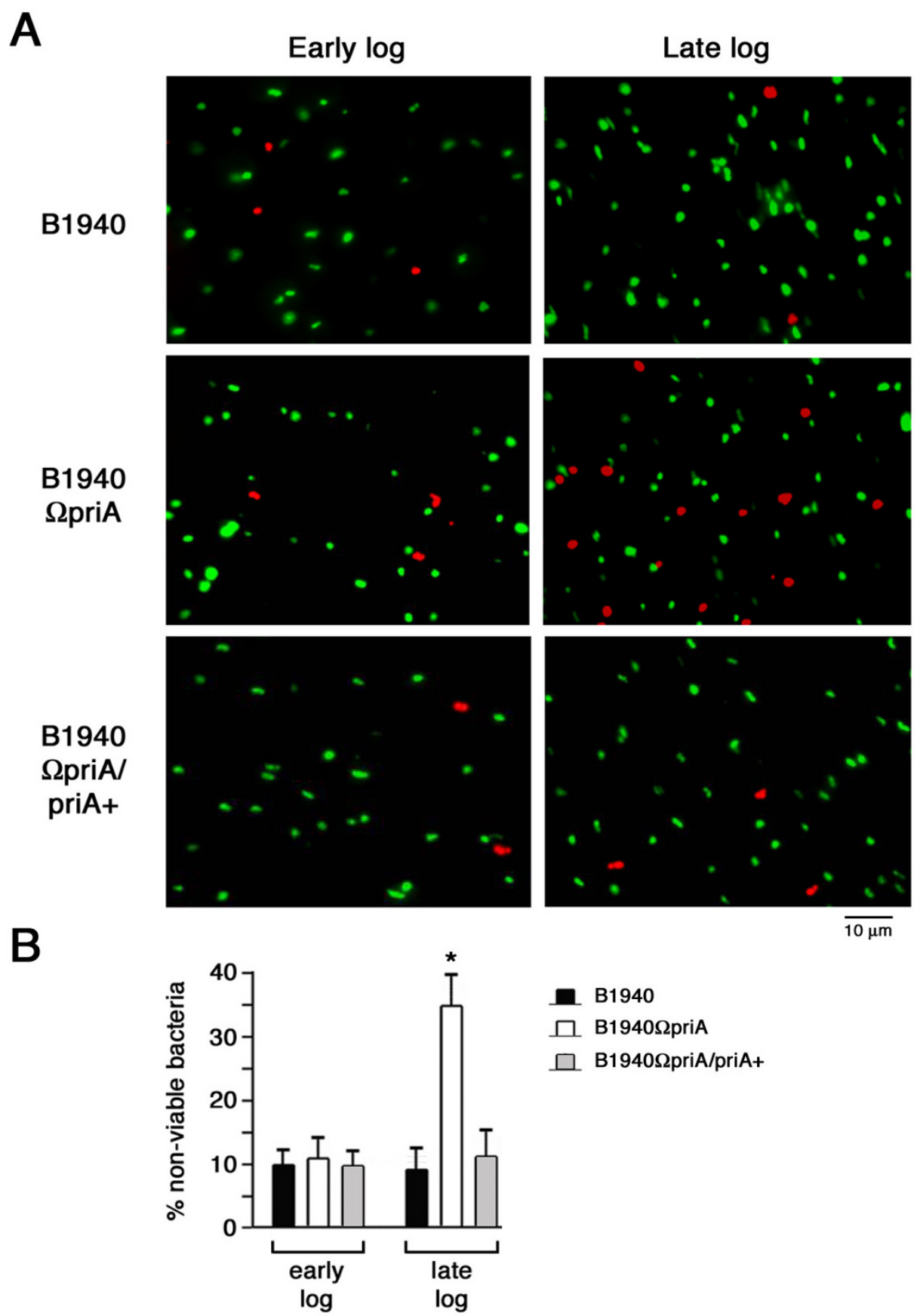

Figure 6

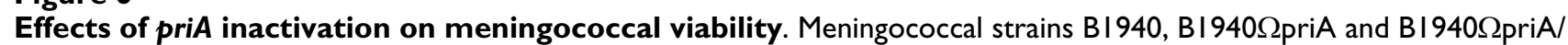
priA+ were grown to either middle $\left(0.5 \mathrm{OD}_{600 \mathrm{~nm}}\right)$ or late $\left(1.0 \mathrm{OD}_{600 \mathrm{~nm}}\right)$ logarithmic phase and then viability was determined by using the Live/Dead BacLight bacterial viability kit (Molecular Probe). (A) Representative images of Live/Dead-stained meningococci: live bacteria fluoresce green, while dead bacteria fluoresce red. (B) Percentages of non-viable meningococci were equal to ratios between bacteria staining positive with propidium iodide (red) and the total stained (red + green) bacteria. Data are shown as mean \pm standard deviation of three experiments. Statistically significant difference between values from BI940

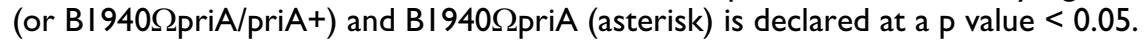



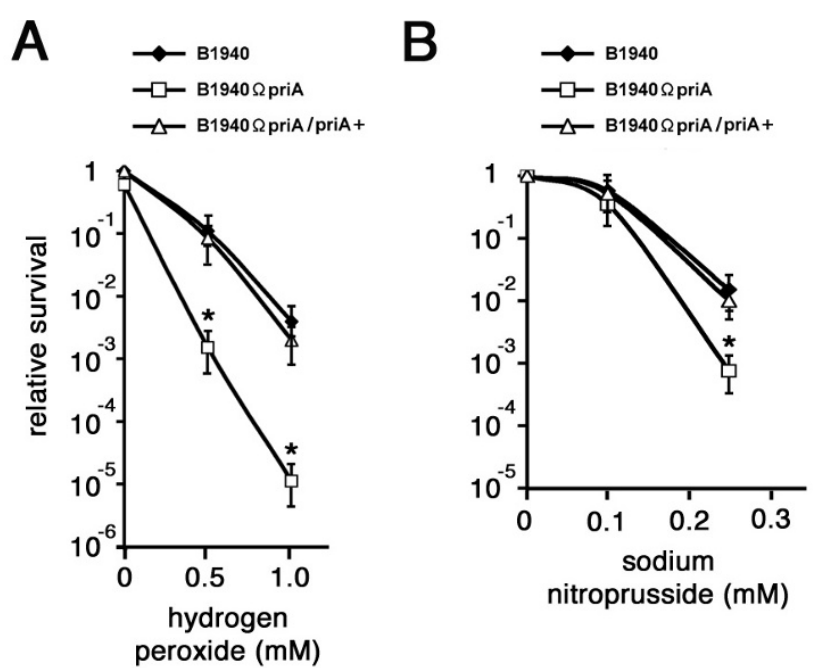

Figure 7

Effects of priA inactivation on sensitivity to oxidative

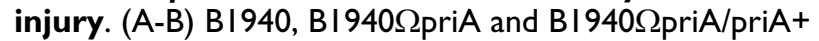
were grown to middle logarithmic phase $\left(0.5 \mathrm{OD}_{600 \mathrm{~nm}}\right.$ corresponding to about $\mathrm{I} \times 10^{9} \mathrm{CFU}$ for both strains) and then exposed for the indicated times to hydrogen peroxide $(A)$ or nitric oxide generator sodium nitroprusside (B) in GC liquid medium with shaking and then viability was determined by recovery of viable bacteria. Data are shown as mean \pm standard deviation from three independent experiments, each with triplicate samples. Statistically significant differences

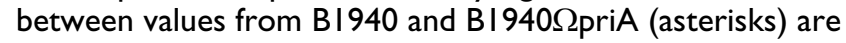
declared at a $\mathrm{p}$ value $<0.05$.

Number CCL-20.2). It should be noted, however, that, as a result of a well known contamination event, HEp2 (thought to be derived from an epidermoid carcinoma of the larinx) and Chang conjunctiva (thought to be derived from normal conjunctiva) cells present HeLa markers and have been established via HeLa cells contamination, as stated by ATCC http://www.atcc.org. These cells were grown at $37^{\circ} \mathrm{C}$ in a $5 \% \mathrm{CO}_{2}$ incubator in DMEM supplemented with inactivated $10 \%$ fetal bovine serum (FBS), 2 $\mathrm{mM}$ L-glutamine, penicillin $\left(50 \mathrm{U} \mathrm{ml}^{-1}\right)$ and streptomycin $\left(50 \mu \mathrm{g} \mathrm{ml}^{-1}\right)$.

N. meningitidis invasion assays were performed as previously described $[8,7]$. In brief, HeLa (or HEp2 or Chang conjunctiva) cells were infected at a multiplicity of infection (MOI) of 50 for $1 \mathrm{~h}$. To start the infection bacteria were centrifuged $(60 \times \mathrm{g})$ onto cells. Cells were washed twice with phosphate-buffered saline (PBS) to eliminate the majority of extracellular bacteria and exposed to gentamicin to kill remaining extracellular bacteria. Cells were then washed extensively with PBS to remove gentamicin and dead extracellular bacteria, and then lysed with saponin. Gentamicin treatment was performed at $100 \mu \mathrm{g}$ $\mathrm{ml}^{-1}$, a concentration 10 -fold above the minimal inhibi-

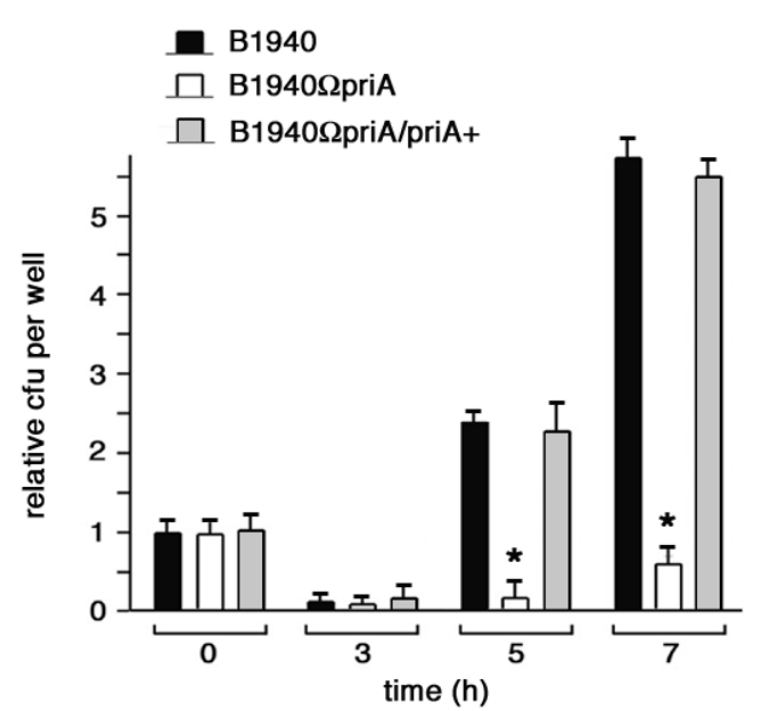

Figure 8

Effects of priA inactivation on survival/growth of meningococcal strains in HeLa cells. HeLa cells (105/ well) were infected with B 1940, B 1940 SpriA or

$\mathrm{B} 1940 \Omega$ priA/priA+ at a $\mathrm{MOI}$ of 50 , treated with gentamicin and re-incubated in DMEM for the indicated times. Bacteria were centrifuged onto cells to start infection. After saponin lysis, CFU from intracellular bacteria were scored. Values are relative to the number of intracellular BI940 at time 0 ( $10^{4}$ bacteria per $2 \times 10^{5}$ cells per $\mathrm{ml}$ ) and are means of at least ten independent experiments made in triplicate with standard errors.

tory concentration (MIC) for $30 \mathrm{~min}$. When required, cells were re-incubated in a fresh culture medium for various time intervals after gentamicin treatment. For quantification, bacteria released by saponin from HeLa cells (intracellular) were plated and colony-forming units (CFU) were counted the day after.

\section{DNA procedures and genetic manipulation}

High-molecular-weight genomic DNA from N. meningitidis strains was prepared as described previously [43]. Oligonucleotides used in this study as primers in PCRs are listed in Table 1. Oligonucleotide synthesis was performed as a service by MWG-Biotech AG Oligo Production. The amplification reactions generally consisted of 35 cycles including $45 \mathrm{~s}$ of denaturation at $94^{\circ} \mathrm{C}, 45 \mathrm{~s}$ of annealing at $65^{\circ} \mathrm{C}$, and $45 \mathrm{~s}$ of extension at $72^{\circ} \mathrm{C}$. They were carried out in a Perkin-Elmer Cetus DNA Thermal Cycler 2400. DNA from strain B1940 was used as a template. Southern blot hybridizations were carried out according to standard protocols [44]. ${ }^{32} \mathrm{P}$ labeling of the DNA fragments was performed by random priming using 


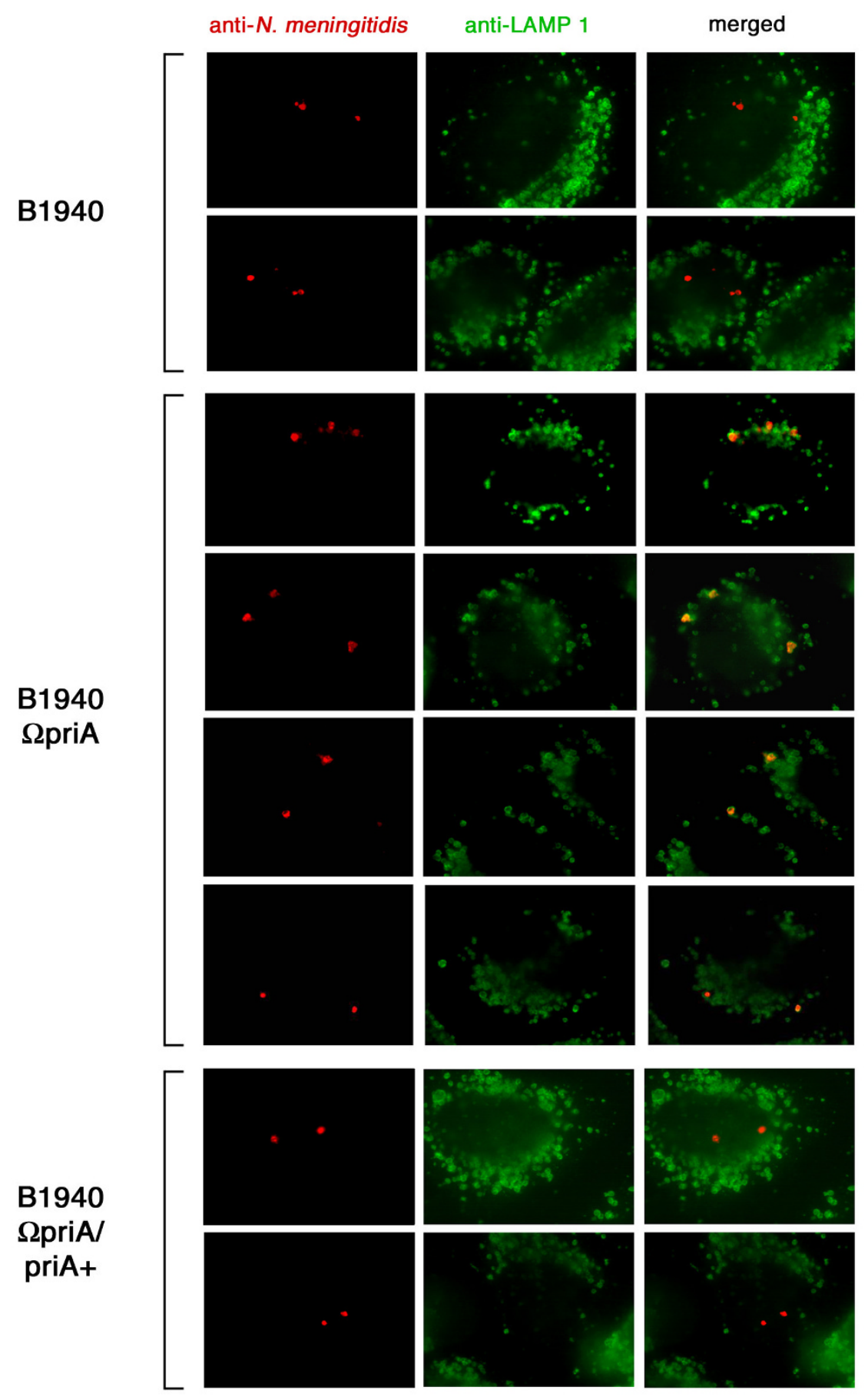

\section{Figure 9}

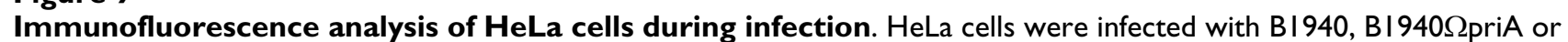

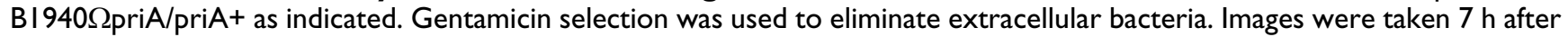
infection. Antibodies against N. meningitidis were used before permeabilization with saponin in combination with a secondary antibody conjugated with $\mathrm{Cy} 5$ and, after permeabilization, with a secondary TRITC-conjugated antibody. Intracellular bacteria were therefore red while extracellular bacteria were expected to be purple (the combination of TRITC and Cy5 signal). In the images all bacteria were intracellular. To detect cellular markers we used anti-LAMPI and a secondary antibody conjugated with FITC. 
the Klenow fragment of the E. coli DNA polymerase I and $[\alpha-32 \mathrm{P}] \mathrm{dATP}$ and $\left[\alpha-{ }^{32} \mathrm{P}\right] \mathrm{dGTP}\left(3,000 \mathrm{Ci} \mathrm{m^{-1 } )}[44]\right.$. DNA sequencing was performed as a service by the MWG Biotech Custom Sequencing Service. Processing of the DNA sequences was performed with the software GeneJockey Sequence Processor (published and distributed by Biosoft). Deduced amino acid sequence similarity searching was performed with the BLAST program using the Conserved Domain Database available at the NCBI.

The Neisseria-E. coli shuttle vectors pDEX and pACNL1 have been previously described $[9,45]$. pACNL1 is a pACYC184 derivative harboring a 1480 bp Sau3AI fragment, spanning the meningococcal leuS- Ydam region in the BamHI site. To construct pDEXpriA, the DNA corresponding to the central segment of the ORF NMB0551 was amplified using the primers NMB0551-1 and NMB0551-2, and the BamHI-restricted 851 bp PCR product was cloned into the BamHI site of pDEX. NMB0551 (priA) was inactivated in B1940 by single cross-over event

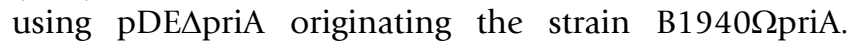
Transformations were performed by using 0.1 to $1 \mu \mathrm{g}$ of plasmid DNA. Transformants were selected on GC agar medium supplemented with erythromycin $\left(7 \mu \mathrm{g} \mathrm{ml}^{-1}\right)$. Successful gene inactivation was demonstrated by Southern blot hybridization. NMB0551-specific probe was obtained by ${ }^{32} \mathrm{P}$ labeling of BamHI-restricted PCR fragment. The size of this fragment was $851 \mathrm{bp}$ (primers

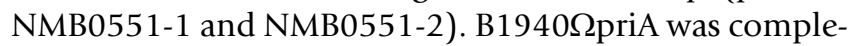
mented by transformation with the integrative plasmid pACpriA. To construct this plasmid, the priA gene (with flanking regulatory elements) was amplified from strain B1940 using the primers NMB0551-3 and NMB0551-4 (Table 1). The XbaI/HindIII-restricted 2565 bp PCR prod- uct was cloned into the XbaI/HindIII sites of pACNL1. Transformants were selected on GC agar medium supplemented with chloramphenicol $\left(5 \mu \mathrm{g} \mathrm{ml}^{-1}\right)$.

\section{RNA procedures}

Total RNAs were extracted from intracellular bacteria during the infection of HeLa cells or control bacteria grown in culture medium as described [8].

The procedure for limited transcriptional analysis has been previously detailed $[9,8]$. Briefly, a partial Sau3AIrestricted genomic library from the serogroup B strain B1940 was constructed. Individual clones were digested and a Southern blot analysis was performed using cDNA probes derived from intracellular bacteria after $8 \mathrm{~h}$ of infection of HeLa cells or control bacteria grown for $8 \mathrm{~h}$ in cell culture medium. This procedure detects mRNA species present in the initial population at a frequency of at least 1 in 200.

The protocol for RT-PCR-DD analysis has been also reported [8]. Briefly, total RNAs were extracted from intracellular bacteria during the infection of HeLa cells or control bacteria grown in cell culture medium, and were used as templates for first-strand cDNA synthesis in the presence of the primers DUS-IN, DUS-OUT, 26L-IN plus 27LIN, 26L-OUT plus 27L-OUT, RS3-IN, RS3-OUT listed in Table 1 . Then second-strand cDNAs synthesis was carried out using the corresponding oligonucleotides and a mixture of random hexamers as primers, and the PCR products were analyzed by polyacrylamide gel electrophoresis. The gel was stained by the silver staining method [44]. The slices of gel containing the differentially expressed transcripts were cut with a sharp scalpel, and the DNA frag-

Table I: Oligonucleotides used in this study

\begin{tabular}{ll}
\hline Name & Sequence $^{\text {a }}$ \\
\hline NMB055I-I & 5'-GATTGGGCGGATCCGGGTTGGATTGAAACAACGGAAGCG-3' \\
NMB055I-2 & 5'-CGTTGGTGCAGGATCCTTTTGGCGGAGCAGTTCGGGCAGCC-3' \\
NMB055I-f & 5'-GCAGGTGTTGTTTCTGTTGCCC-3' \\
NMB055I-r & 5'-CAAATAATCCTGCGTGCGCTTG-3' \\
NMB055I-3 & 5'-GAATAGGTCTAGACCAAACGCGCTTTCAAAGAGGCGG-3' \\
NMB055I-4 & 5'-GGGCGAAAGCTTTTACAGACGATCCGGAATAAAAATG-3' \\
DUS-IN & 5'-GCCGTCTGAA-3' \\
DUS-OUT & 5'-TTCAGACGGC-3' \\
26L-IN & 5'-GTGGATTAACAAAAATCAGGAC-3' \\
26L-OUT & 5'-GTCCTGATTTTTGTTAATCCAC-3' \\
27L-IN & 5'-GTGGATTAAATTTAAATCAGGAC-3' \\
27L-OUT & 5'-GTCCTGATTTAAATTTAATCCAC-3' \\
RS3-IN & 5'-CATTCCCGCGCAGGCGGGAATC-3' \\
RS3-OUT & 5'-GATTCCCGCCTGCGCGAATG-3' \\
I6Suniv-I & 5'-CAGCAGCCGCGGTAATAC-3' \\
I6Suniv-2 & 5'-CCGTCAATTCCTTTGAGTTT-3' \\
I6S-r & 5'-CTACGCATTTCACTGCTACACG-3'
\end{tabular}

aRestriction sites $\mathrm{Xbal}$ and HindIII are underlined. 
ments were allowed to diffuse into $100 \mu \mathrm{l}$ of sterile water at $37^{\circ} \mathrm{C}$ for $4 \mathrm{~h}$ under stirring. The eluted DNA was ethanol precipitated using glycogen as a carrier. Then, it was used as a template in a PCR with the corresponding primers. The positive amplicons were cloned in a pGEM easy vector (Promega) and sequenced.

RT-PCR slot blot analysis of meningococcal priA-specific transcripts during infection of HeLa cells was performed as previously described [8]. To prepare gene-specific cDNA probes, the RNAs were subjected to reverse transcription using the oligonucleotides NMB0551-2 or 16Suniv-2 (loading control) as primers. The labeling procedure consisted of a PCR, where $2 \mu \mathrm{l}$ of cDNA was used as template in a $50 \mu \mathrm{l}$ mixtures containing $0.2 \mathrm{mM}$ of each dCTP and dTTP, $2.5 \mu \mathrm{M}$ of each dATP and dGTP, $0.12 \mu \mathrm{M}$

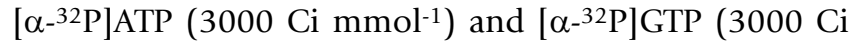
$\mathrm{mmol}^{-1}$ ), $0.2 \mu \mathrm{M}$ forward NMB0551-1 or 16Suniv-1 primers, and $0.05 \mathrm{U} \mathrm{l}^{-1}$ of Taq polymerase (Perkin Elmer S.p.A). The amplification reaction consisted of 20-25 cycles including $45 \mathrm{sec}$ of denaturation at $94^{\circ} \mathrm{C}, 45 \mathrm{sec}$ of annealing at $55^{\circ} \mathrm{C}$ and $45 \mathrm{sec}$ of extension at $72^{\circ} \mathrm{C}$. The number of cycles was critical to operate in the linear range of the PCR, and it was determined in preliminary experiments. The ${ }^{32} \mathrm{P}$-labeled cDNA probes were hybridized to different amounts (0.05 to $100 \mathrm{ng})$ of denatured NMB0551 (priA)- or 16S rRNA gene-specific DNA fragments generated by PCR with the corresponding primer pairs NMB0551-1/NMB0551-2, and 16Suniv-1/16Suniv2, and fixed onto positively charged Hybond-N+ nylon membranes. The hybridization reactions were carried out in Church buffer [44] at $63^{\circ} \mathrm{C}$. Semi-quantitative analysis was performed by directly counting the radioactivity bands by a PhosphoImager SI (Molecular Dynamics, Inc., Sunnyvale, CA).

Semi-quantitative analysis of the priA-specific transcript, normalized to $16 \mathrm{~S}$ rRNA, was also performed by real-time RT-PCR. Total RNAs $(1 \mu \mathrm{g})$ from either intracellular or control bacteria grown in cell culture medium were reverse-transcribed by using random hexamer $(2.5 \mu \mathrm{M})$ with Superscript RT (Invitrogen). About $0.1-1 \%$ of each RT reaction was used to run real-time PCR on a SmartCycler System (Cepheid) with SYBR $^{\circledR}$ Green JumpStart Taq ReadyMix (Sigma-Aldrich) and the primer pairs 16Suniv1/16S-r (specific for 16S rRNA) and NMB0551-f/ NMB0551-r (specific for priA). PCR products were $185 \mathrm{bp}$ for 16Suniv-1/16S-r, and 143 bp for NMB0551-f/ NMB0551-r. Real-time PCR samples were run in triplicate. The real-time PCR conditions were: $30 \mathrm{sec}$ at $94^{\circ} \mathrm{C}, 30 \mathrm{sec}$ at $55^{\circ} \mathrm{C}, 30 \mathrm{sec}$ at $72^{\circ} \mathrm{C}$ for 35 cycles; detection of PCR products was performed at $83^{\circ} \mathrm{C}$.

\section{Bacteria viability assay}

The viability of meningococcal strains was determined by using the Live/Dead BacLight bacterial viability kit (Molecular Probe). To this purpose, meningococci were grown to either middle $\left(0.5 \mathrm{OD}_{600 \mathrm{~nm}}\right)$ or late $\left(1.0 \mathrm{OD}_{600}\right.$ $\mathrm{nm}$ ) logarithmic phase in $50 \mathrm{ml}$ of GC medium with $1 \%$ Polyvitox as described above. Then $1 \mathrm{ml}$ of bacterial suspension was collected by low-speed centrifugation. Meningococci were washed, re-suspended in $1 \mathrm{ml} 0.9 \%$ $\mathrm{NaCl}$ and mixed with an equal volume of $2 \mathrm{X}$ working solution of Live/Dead BacLight containing a 1:1 mixture of SYTO9 and propidium iodide. After 15 min dark incubation, $5 \mu$ l of mounted specimens were viewed with a Nikon Optiphot-2 microscope with an episcopic-fluorescence attachment (EFD-3, Nikon).

\section{Hydrogen peroxide and sodium nitroprusside sensitivity assays}

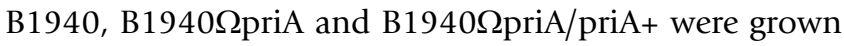
to middle logarithmic phase $\left(0.5 \mathrm{OD}_{600 \mathrm{~nm}}\right.$ corresponding to about $1 \times 10^{9} \mathrm{CFU}$ ). Then, $5 \mathrm{ml}$ aliquots ("input" CFU $=5 \times 10^{9} \mathrm{CFU}$ for each strains) were placed into $15-\mathrm{ml}$ conical tubes. $\mathrm{H}_{2} \mathrm{O}_{2}$ was added to the tubes at final concentrations of $0,0.5$, or $1 \mathrm{mM}$, and tubes were incubated with shaking for $20 \mathrm{~min}$ at $37^{\circ} \mathrm{C}$. Cultures were immediately centrifuged and pellets were re-suspended into $5 \mathrm{ml}$ GC broth. These re-suspensions were serially diluted into GC broth and spotted onto GC agar. The plates were incubated at $37^{\circ} \mathrm{C}$ in a $5 \% \mathrm{CO}_{2}$ incubator and the colonies were counted after 24 h of growth. For the sodium nitroprusside sensitivity assay, dilutions of freshly grown liquid cultures of $N$. meningitidis to middle logarithmic phase $\left(0.5 \mathrm{OD}_{600 \mathrm{~nm}}\right.$ corresponding to about $\left.1 \times 10^{9} \mathrm{CFU}\right)$ were immediately spread onto GC agar plates containing $1 \%$ Polyvitox and the nitric oxide generator. Plates were incubated in an atmosphere of $5 \% \mathrm{CO}_{2}$ at $37^{\circ} \mathrm{C}$.

\section{Immunufluorescence microscopy}

Immunofluorescence analysis was performed as previously described to distinguish between extracellular and intracellular bacteria [7]. In brief, after infection, cells were washed once with PBS, and fixed with 3\% paraformaldehyde. For staining of extracellular bacteria, incubation with primary antibodies was carried out for $20 \mathrm{~min}$ at room temperature. After washes in PBS, cells were incubated with secondary antibodies for $20 \mathrm{~min}$ in the dark, at room temperature. Subsequently, cells were permeabilized with saponin, incubated with primary antibodies to stain bacteria or intracellular markers and then incubated with secondary antibodies. Rabbit polyclonal anti-N. meningitidis antibody was from ViroStat while monoclonal H4A3 anti-LAMP1 was obtained from the Developmental Studies Hybridoma Bank at the University of Iowa. Primary and secondary antibodies were used at a 1:500 dilution. Mounted coverslips were examined using 
a Nikon Optiphot-2 microscope with an episcopic-fluorescence attachment (EFD-3, Nikon). Image processing was carried out with Adobe Photoshop version 7.0.

\section{Scanning electron microscopy}

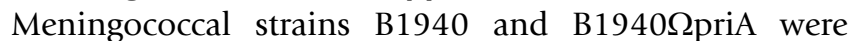
grown to late $\left(1.0 \mathrm{OD}_{600 \mathrm{~nm}}\right)$ logarithmic phase in $50 \mathrm{ml}$ of GC medium with 1\% Polyvitox as described above. Then $1 \mathrm{ml}$ of bacterial suspension was collected by centrifugation. For SEM observations, meningococci were fixed with $1 \%$ glutaraldehyde, washed three times with distilled water by centrifugation, dehydrated in a graded alcohol series and critical-point dried. The sample was then mounted on Aluminum stubs, sputter-coated with gold and examined at an accelerating voltage of $20 \mathrm{kV}$ with a Jeol 6060LV Scanning Electron microscope.

\section{Authors' contributions}

AT and MDS carried out the experiments, CB participated in the design of the study and its coordination, PA conceived the study and wrote the manuscript. All authors read and approved the final manuscript.

\section{Competing interests}

The authors declare that they have no competing interests.

\section{Acknowledgements}

The authors are grateful to Miss Victoria Blake for English editing of the manuscript. This work was partially supported by grants from Italian MIUR to C. B. and P. A. (60\%, COFIN 2004, COFIN 2006). The authors have no conflicting financial interests.

\section{References}

I. Merz AJ, So M: Interactions of pathogenic Neisseriae with epithelial cell membranes. Annu Rev Cell Dev Biol 2000, 16:423-457.

2. Dehio C, Gray-Owen SD, Meyer TF: Host cell invasion by pathogenic Neisseriae. Subcell Biochem 2000, 33:61-96.

3. Nassif $X$, Bourdoulous $S$, Eugène $E$, Couraud PO: How do extracellular pathogens cross the blood-brain barrier? Trends Microbiol 2002, 1 0:227-232

4. Tinsley C, Nassif $X$ : Meningococcal pathogenesis: at the boundary between the pre- and post-genomic eras. Curr Opin Microbiol 200I, 4:47-52.

5. Tzeng YL, Stephens DS: Epidemiology and pathogenesis of Neisseria meningitidis. Microbes Infect 2000, 2:687-700.

6. Hauck CR, Meyer TF: 'Small' talk: Opa proteins as mediators of Neisseria - host-cell communication. Curr Opin Microbiol 2003, 6:43-49.

7. Spinosa MR, Progida C, Talà A, Cogli L, Alifano P, Bucci C: The Neisseria meningitidis capsule is important for intracellular survival in human cells. Infect Immun 2007, 75:3594-3603.

8. Monaco C, Talà A, Spinosa MR, Progida C, De Nitto E, Gaballo A, Bruni $C B$, Bucci $C$, Alifano P: Identification of a meningococcal L-glutamate $A B C$ transporter operon essential for growth in low-sodium environments. Infect Immun 2006, 74: I725-I740.

9. Pagliarulo C, Salvatore P, De Vitis LR, Colicchio R, Monaco C, Tredici $M$, Talà A, Bardaro M, Lavitola A, Bruni CB, Alifano P: Regulation and differential expression of gdhA encoding NADP-specific glutamate dehydrogenase in Neisseria meningitidis clinical isolates. Mol Microbiol 2004, 5 I: 1757-1772.

10. Schekman R, Weiner JH, Weiner A, Kornberg A: Ten proteins required for conversion of phiX 174 single-stranded DNA to duplex form in vitro. Resolution and reconstitution. I Biol Chem 1975, 250:5859-5865.
II. Wickner S, Hurwitz ]: Conversion of phiX I 74 viral DNA to double-stranded form by purified Escherichia coli proteins. Proc Natl Acad Sci USA 1974, 71:4 I20-4I 24.

12. Marians KJ: PriA: at the crossroads of DNA replication and recombination. Prog Nucleic Acid Res Mol Biol 1999, 63:39-67.

13. Lovett ST: Connecting replication and recombination. Mol Cell 2003, I I:554-556.

14. Lovett ST: Filling the gaps in replication restart pathways. Mol Cell 2005, 17:75I-752.

15. de Jonge MI, Hamstra HJ, van Alphen L, Dankert J, Ley P van der: Mapping the binding domains on meningococcal Opa proteins for CEACAMI and CEA receptors. Mol Microbiol 2003, 50:1005-1015.

16. Massari P, King CA, Ho AY, Wetzler LM: Neisserial PorB is translocated to the mitochondria of HeLa cells infected with Neisseria meningitidis and protects cells from apoptosis. Cell Microbiol 2003, 5:99-109.

17. Pridmore AC, Wyllie DH, Abdillahi F, Steeghs L, Ley $\mathrm{P}$ van der, Dower SK, Read RC: A lipopolysaccharide-deficient mutant of Neisseria meningitidis elicits attenuated cytokine release by human macrophages and signals via toll-like receptor (TLR) 2 but not via TLR4/MD2. J Infect Dis 200I, 183:89-96.

18. Pridmore AC, Jarvis GA, John CM, Jack DL, Dower SK, Read RC: Activation of toll-like receptor 2 (TLR2) and TLR4/MD2 by Neisseria is independent of capsule and lipooligosaccharide (LOS) sialylation but varies widely among LOS from different strains. Infect Immun 2003, 7 I:390I-3908.

19. Virji M, Evans D, Hadfield A, Grunert F, Teixeira AM, Watt SM: Critical determinants of host receptor targeting by Neisseria meningitidis and Neisseria gonorrhoeae: identification of Opa adhesiotopes on the $\mathbf{N}$-domain of CD66 molecules. Mol Microbiol 1999, 34:538-55I.

20. Wyllie DH, Kiss-Toth E, Visintin A, Smith SC, Boussouf S, Segal DM, Duff GW, Dower SK: Evidence for an accessory protein function for Toll-like receptor $I$ in anti-bacterial responses. J Immunol 2000, 165:7125-132.

21. Dietrich G, Kurz S, Hubner C, Aepinus C, Theiss S, Guckenberger M, Panzner U, Weber J, Frosch M: Transcriptome analysis of Neisseria meningitidis during infection. J Bacteriol 2003, I 85: I 55-164.

22. Tzeng YL, Datta AK, Strole CA, Lobritz MA, Carlson RW, Stephens DS: Translocation and surface expression of lipidated serogroup B capsular Polysaccharide in Neisseria meningitidis. Infect Immun 2005, 73: I 49I-I 505.

23. Schmitt C, Turner D, BoesI M, Abele M, Frosch M, Kurzai O: A functional two-partner secretion system contributes to adhesion of Neisseria meningitidis to epithelial cells. J Bacteriol 2007, I 89:7968-7976.

24. Lee EH, Kornberg A: Replication deficiencies in priA mutants of Escherichia coli lacking the primosomal replication $n$ ' protein. Proc Natl Acad Sci USA I 991, 88:3029-3032.

25. Shaw JH, Falkow S: Model for invasion of human tissue culture cells by Neisseria gonorrhoeae. Infect Immun 1988, 56:1625-1632.

26. Williams JM, Chen GC, Zhu L, Rest RF: Using the yeast twohybrid system to identify human epithelial cell proteins that bind gonococcal Opa proteins: intracellular gonococci bind pyruvate kinase via their Opa proteins and require host pyruvate for growth. Mol Microbiol 1998, 27: I7I-I86.

27. Lin L, Ayala P, Larson J, Mulks M, Fukuda M, Carlsson SR, Enns C, So M: The Neisseria type 2 IgAI protease cleaves LAMPI and promotes survival of bacteria within epithelial cells. Mol Microbiol 1997, 24: 1083-1094.

28. Smith HO, Gwinn ML, Salzberg SL: DNA uptake signal sequences in naturally transformable bacteria. Res Microbiol 1999, I 50:603-616.

29. Stryer L: Biochemistry. 2nd edition. New York: WH Freeman; 1988.

30. Hill JC: Effect of glutamate on exogenous citrate catabolism of Neisseria meningitidis and of other species of Neisseria. J Bacteriol I97I, 106(3):819-823.

31. Cox MM, Goodman MF, Kreuzer KN, Sherratt DJ, Sandler SJ, Marians $\mathrm{KJ}$ : The importance of repairing stalled replication forks. Nature 2000, 404:37-4I.

32. Kuzminov A: Recombinational repair of DNA damage in Escherichia coli and bacteriophage lambda. Microbiol Mol Biol Rev 1999, 63:751-813. 
33. Nurse $\mathrm{P}$, Zavitz $\mathrm{KH}$, Marians $\mathrm{KJ}$ : Inactivation of the Escherichia coli priA DNA replication protein induces the SOS response. J Bacteriol I99I, 173:6686-6693.

34. Kline KA, Seifert HS: Mutation of the priA gene of Neisseria gonorrhoeae affects DNA transformation and DNA repair. J Bacteriol 2005, 187:5347-5355.

35. Seib KL, Tseng HJ, McEwan AG, Apicella MA, Jennings MP: Defenses against oxidative stress in Neisseria gonorrhoeae and Neisseria meningitidis: distinctive systems for different lifestyles. J Infect Dis 2004, 190:136-147.

36. Overton TW, Whitehead R, Li Y, Snyder LA, Saunders NJ, Smith H, Cole JA: Coordinated regulation of the Neisseria gonorrhoeaetruncated denitrification pathway by the nitric oxide-sensitive repressor, NsrR, and nitrite-insensitive NarQ-NarP. J Biol Chem 2006, 28 I:33 I I5-33 I 26.

37. Rock JD, Mahnane MR, Anjum MF, Shaw JG, Read RC, Moir JW: The pathogen Neisseria meningitidis requires oxygen, but supplements growth by denitrification. Nitrite, nitric oxide and oxygen control respiratory flux at genetic and metabolic levels. Mol Microbiol 2005, 58:800-809.

38. De Groote MA, Granger D, Xu Y, Campbell G, Prince R, Fang FC Genetic and redox determinants of nitric oxide cytotoxicity in a Salmonella typhimurium model. Proc Natl Acad Sci USA 1995, 92:6399-6403

39. Schapiro JM, Libby SJ, Fang FC: Inhibition of bacterial DNA replication by zinc mobilization during nitrosative stress. Proc Natl Acad Sci USA 2003, 100:8496-8501.

40. Stevanin TM, Moir JWB, Read RC: Nitric oxide detoxification systems enhance survival of Neisseria meningitidis in human macrophages and in nasopharyngeal mucosa. Infect Immun 2005, 73:3322-3329.

41. Eskelinen EL: Roles of LAMP-I and LAMP-2 in lysosome biogenesis and autophagy. Mol Aspects Med 2006, 27:495-502

42. Frosch M, Schultz E, Glenn-Calvo E, Meyer TF: Generation of capsule-deficient Neisseria meningitidis strains by homologous recombination. Mol Microbiol 1990, 4:1215-1218.

43. Bucci C, Lavitola A, Salvatore P, Del Giudice L, Massardo DR, Brun $C B$, Alifano $P$ : Hypermutation in pathogenic bacteria: frequent phase variation in meningococci is a phenotypic trait of a specialized mutator biotype. Mol Cell 1999, 3:435-445.

44. Sambrook J, Russell DW: Molecular Cloning. A Laboratory Manual. 2nd edition. New York: Cold Spring Harbor Laboratory Press; 200I.

45. Salvatore P, Cantalupo G, Pagliarulo C, Tredici M, Lavitola A, Bucci C, Bruni $C B$, Alifano $P$ : A new vector for insertion of any DNA fragment into the chromosome of trasformable Neisseria. Plasmid 2000, 44:275-279.

Publish with Bio Med Central and every scientist can read your work free of charge

"BioMed Central will be the most significant development for disseminating the results of biomedical research in our lifetime. "

Sir Paul Nurse, Cancer Research UK

Your research papers will be:

- available free of charge to the entire biomedical community

- peer reviewed and published immediately upon acceptance

- cited in PubMed and archived on PubMed Central

- yours - you keep the copyright

Submit your manuscript here:

http://www.biomedcentral.com/info/publishing_adv.asp
BioMedcentral 